\title{
SATURN / TITAN RENDEZVOUS : A SOLAR-SAIL AEROCAPTURE MISSION
}

\author{
Dr. Gregory L. Matloff \\ Phys. \& Bio.Sci. Dept,NYC Coll. of Technology,300 Jay St.,Bklyn,NY 11201,USA \\ gregmat@hotmail.com \\ Dr. Travis Taylor \\ BAE Systems, 310 Voyager Way, Huntsville, AL, 35806, USA \\ travis.taylor@baesystems.com \\ Dr. Conley Powell \\ BAE Systems, 310 Voyager Way, Huntsville, AL, 35806, USA \\ conley.powell@baesystems.com
}

Abstract A low-mass Titan orbiter is proposed that uses conservative or optimistic solar sails for all post-Earthescape propulsion. After accelerating the probe onto a trans-Saturn trajectory, the sail is used parachute style for Saturn capture during a pass through Saturn's outer atmosphere. If the apoapsis of the Saturn-capture orbit is appropriate, the aerocapture maneuver can later be repeated at Titan so that the spacecraft becomes a satellite of Titan. An isodensity- atmosphere model is applied to screen aerocapture trajectories.

Huygens/Cassini should greatly reduce uncertainties regarding the upper atmospheres of Saturn and Titan.

\section{INTRODUCTION : OUTLINE OF A} MISSION :

We propose a solar-photonsail mission to the Saturn / Titan system with the following mission phases, as shown in Fig. 1. Mission Phase $\mathrm{I}$ is Earth-escape using a
Delta / Atlas class rocket with the sail furled. Once on its parabolic or hyperbolic Earth-escape trajectory, the sail is unfurled in Mission Phase II and the sail is accelerated towards Saturn. Mission Phase III is the cruise to Saturn, in which the sail might be oriented parallel to the direction of travel. In Mission Phase IV, the sail skims the outer atmosphere of Saturn, with the sail oriented parachute-fashion, normal to the direction of travel. This maneuver decelerates the spacecraft (s/c), allowing it to enter an eccentric orbit around Saturn, with the apoapsis at Titan. The sail or a small thruster could be used to raise the periapsis of this orbit above the upper atmosphere of Saturn. In the final mission phase, Phase IV, the sailcraft skims the upper atmosphere of Titan decelerating to become a satellite of this object.

For simplicity, all calculations assume that the Earth-escape trajectory is parabolic, although Vulpetti has demonstrated the advantages of a slightly hyperbolic Earth-escape trajectory. ${ }^{1}$ The baseline mission (Configuration 1) is configured like Matloff's 
"Persephone" Kuiper-belt-probe proposal, ${ }^{2}$ which itself is derived from NASA's Interstellar probe: ${ }^{3}$

Total $\mathrm{s} / \mathrm{c}$ mass $\left(M_{\mathrm{s} / \mathrm{c}}\right): 300 \mathrm{~kg}$, Sail Mass $\left(M_{\text {sail }}\right): 150 \mathrm{~kg}$

Structure/payload mass $\left(M_{\text {pay }}\right): 150$

$\mathrm{kg}$, Science payload $\left(\mathrm{M}_{\mathrm{sci}}\right): 30 \mathrm{~kg}$

The sail is assumed to have a radius of $219 \mathrm{~m}$. Thus, the sail-film areal mass thickness $\left(\sigma_{\text {sail }}\right)$ is $0.001 \mathrm{~kg} / \mathrm{m}^{2}$, which might be achievable by 2010 .

The spacecraft areal mass thickness $\left(\sigma_{\mathrm{s} / \mathrm{c}}\right)$ is $0.002 \mathrm{~kg} / \mathrm{m}^{2}$.

After early discussion of this concept with the solar-sail team at NASA Marshall Space Flight Center (MSFC), Huntsville,AL, it was decided to examine a much more conservative configuration (Configuration 2). This sailcraft is achievable using current technology and has a spacecraft areal mass thickness up by a factor of $15 X, \sigma_{s / c}$ $=0.03 \mathrm{~kg} / \mathrm{m}^{2}$.

\section{(II) SAIL ACCELERATION :}

The sail is unfurled in space after insertion into the Earth-escape trajectory. We assume that both configurations enter solar orbit at a velocity relative to the Sun of 30 $\mathrm{km} / \mathrm{sec}$.

The Configuration 1 sail is then oriented normal to the Sun to accelerate to solar escape velocity (42 km/sec relative to the Sun). For an approximate acceleration time of one month at $1 \mathrm{AU}$ from the Sun, the average sailcraft acceleration $\left(\mathrm{a}_{\text {sail }}\right)$ is $0.0046 \mathrm{~m} / \mathrm{sec}^{2}$ or $0.00047 \mathrm{~g}$. Sailcraft acceleration is written:

$$
a_{\text {sail }}=(1+\kappa) S_{\mathrm{r}} /\left(c \sigma_{\mathrm{s} / \mathrm{c}}\right) \text {, }
$$

where $\mathrm{K}$ is sail reflectivity, $\mathrm{S}_{\mathrm{r}}$ is the solar constant $\left(1368 \mathrm{w} / \mathrm{m}^{2}\right)$ and $\mathrm{c}$ is the speed of light $\left(3 \times 10^{8} \mathrm{~m} / \mathrm{sec}\right)$. For a sail reflectivity of 0.9 and a spacecraft areal mass thickness of $0.002 \mathrm{~kg} / \mathrm{m}^{2}$, the acceleration is approximately equal to 0.0046 $\mathrm{m} / \mathrm{sec}^{2}$. One option for this mission phase is to inject the spacecraft into a "sundiver" trajectory and unfurl the sail closer to the Sun, which would result in a less demanding sail areal mass thickness or a higher acceleration.

Configuration 2 has too high an areal mass thickness to reach solar escape velocity from $1 \mathrm{AU} .{ }^{4}$ Instead, we choose to use the sail to inject the sailcraft into a trans-Saturn Hohmann transfer trajectory. Referring to Bate et $a^{5}$, the orbital energy of Hohmann Transfer ellipse $\left(E_{t}\right)$ between Earth's solar orbit (distance Rearth from the Sun and Saturn's solar orbit (distance $\mathbf{R}_{\text {sat }}$ from the Sun) is written:

$$
E_{t}=G_{\text {sun }} /\left(R_{\text {earth }}+R_{\text {sat }}\right) \text {, }
$$

where $\mathrm{G}$ is the Gravitational constant (6.67 X $10^{-11}$ MKS Units and Msun is the solar mass $(1.99 \times 1030 \mathrm{~kg})$. starting from Rearth $=1 \mathrm{AU}=1.5 \mathrm{X}$ $10^{11} \mathrm{~m}$ and terminating at $R_{\text {sat }}=9.5$ $A U=1.43 \times 10^{12} \mathrm{~m}$, we find that $E_{\mathrm{t}}=$ $8.4 \times 10^{7}$ Joule/kg. also from Ref. 5 , the Hohmann-ellipse perihelion velocity is expressed as :

$$
V_{\text {peri }}=\left[2\left(G M_{\text {sun }} / R_{\text {earth }}\right)+E_{t}\right]^{1 / 2} \text {. }
$$

Substituting in Eq. (2), we find that $V_{\text {peri }}=40 \mathrm{~km} / \mathrm{sec}$. Since the Earth orbits the sun at $30 \mathrm{~km} / \mathrm{sec}$, the sail 
must supply an additional $10 \mathrm{~km} / \mathrm{sec}$ to insert the spacecraft into a transSaturn Hohmann transfer ellipse.

Assuming once again a 0.9 reflectivity and substituting in Eq. (1), we find that at $1 \mathrm{AU}$, the $0.03 \mathrm{~kg} / \mathrm{m}^{2}$ areal-mass-thickness Configuration 2 characteristic sailcraft acceleration is $3 \times 10^{-4} \mathrm{~m} / \mathrm{sec}^{2}$. Since the sail wil rarely be normal to the Sun, we halve this acceleration and extimate that the time required to accelerate from 30 to $40 \mathrm{~km} / \mathrm{sec}$ is 2.2 years.

\section{(III) CRUISING TO SATURN:}

The lower mass Configuration 1 sail cruises to Saturn at solarparabolic velocity. To estimate travel time to Saturn at parabolic velocity in years, we apply Eq. (1.3) of Ref. 6 :

$$
\mathrm{T}_{\text {year }}=0.077 \mathrm{R}_{\text {sat,au }}{ }^{3 / 2},
$$

where the Sun's distance from Saturn is in Astronomical Units. Since Saturn is 9.5 AU from the Sun, we substitute in Eq. (4) and learn that the cruise time to Saturn is approximately 2.3 years.

Configuration 1 cruises to Saturn along a Hohmann transfer ellipse. Bate et $\mathrm{al}^{5}$ tabulates the Hohmann-transfer cruise time to Saturn as 6.04 years.

Thus, the total duration of the post-launch voyage to Saturn is < 2.5 years for Configuration 1 . The more conservative Configuration 2 spacecraft requires $<8.5$ years to reach Saturn.

Saturn orbits the Sun at 9.65 $\mathrm{km} / \mathrm{sec}$. The Configuration 1 preencounter spacecraft velocity relative to the planet is therefore about 13.65 $\mathrm{km} / \mathrm{sec}$. The velocity of the Configuration 2 spacecraft relative to the Sun at the Saturn-aphelion of its Hohmann transfer ellipse can be calculated from Eq. (3) by replacing Earth's solar distance by Saturn's. We calculate this velocity as $\mathbf{4 . 2}$ $\mathrm{km} / \mathrm{sec}$. Just prior to Saturn encounter therefore, the Configuration 2 spacecraft has a velocity relative to Saturn $\left(V_{a p}\right)$ of $5.65 \mathrm{~km} / \mathrm{sec}$.

\section{(IV) AEROCAPTURE THEORY}

From Ref. 6, at the start of the aerocapture maneuver, the spacecraft's velocity relative to the planet $\left(V_{s / c, 0}\right)$ is $\left[V_{\text {sat,es }}{ }^{2}+V_{a p}{ }^{2}\right)^{1 / 2}$, where $V_{\text {sat,es }}$ is the escape velocity at Saturn's visible cloud tops ( 35.48 $\mathrm{km} / \mathrm{sec}$ ). At the start of aerocapture, the Configuration 1 spacecraft velocity relative to Saturn is therefore about $38 \mathrm{~km} / \mathrm{sec}$. For the spacecraft to become a satellite of Saturn, it's velocity relative to Saturn $\left(V_{s / c, f}\right)$ must be reduced by $2.52 \mathrm{~km} / \mathrm{sec}$ during aerocapture.

The Configuration 2 sailcraft's velocity relative to Saturn at the start of aerocapture is about $\mathbf{3 5 . 9 0}$ $\mathrm{km} / \mathrm{sec}$. For aerocapture, this must be reduced by about $0.42 \mathrm{~km} / \mathrm{sec}$.

During aerocapture, the sail is oriented broadside to the direction of travel, parachute fashion. When the spacecraft moves at a velocity $V_{s / c}$ through a planetary atmosphere with density $\rho_{\text {atm }}$, the drag deceleration can be approximated: ${ }^{7}$

$A_{d e c}=-\rho_{a t m} V_{s / c} 2 / \sigma_{s / c}$

In 1996, a Finite-Element analysis was performed by Cassenti et al 
that evaluated the maximum accelerations that could be tolerated by various solar-photon-sail designs. ${ }^{8}$ All designs considered could tolerate upwards of $25 \mathrm{~m} / \mathrm{sec}^{2}$ $(2.5 \mathrm{~g})$.

Somewhat more conservatively, we limit average Configuration 1 sailcraft deceleration to $2 \mathrm{~g}\left(20 \mathrm{~m} / \mathrm{sec}^{2}\right)$. About 126 seconds are required to decelerate for planetary capture, assuming near-constant deceleration. During deceleration, the sailcraft moves at an average velocity $\left(\mathrm{V}_{\mathrm{s} / \mathrm{c} \text {, av }}\right)$ of $\mathbf{3 6 . 7 4}$ $\mathrm{km} / \mathrm{sec}$ relative to Saturn and travels a deceleration distance $\left(D_{a t m}\right)$ of about $4,630 \mathrm{~km}$.

Because the Configuration 2 sailcraft must shed less velocity to be captured by Satum, we limit its average deceleration to $4.25 \mathrm{~m} / \mathrm{sec}^{2}$. Aerocapture deceleration requires approximately 99 seconds. The average Configuration 2 sailcraft velcocity during deceleration $\left(\mathrm{V}_{\mathrm{s} / \mathrm{c}, \mathrm{av}}\right)$ is about $35.7 \mathrm{~km} / \mathrm{sec}$. During deceleration, the Configuration 2 sailcraft traverses about $3534 \mathrm{~km}$.

\section{(V) AN ISODENSITY PLANETARY-} ATMOSPHERE MODEL

For trajectory-profile screening purposes, it would be useful to have a model of aerocapture in which the average deceleration is essentially constant. From Eq. (5), for a fixed sailcraft areal mass thickness, near-constant deceleration implies a near-constant atmospheric density.

The density of a planet's atmosphere at height $h_{2}$ above its visible surface can be related to its density at a reference height $h_{1}$, and density scale height $H$ :

$$
\rho_{\mathrm{atm}, \mathrm{h} 2}=\rho_{\mathrm{atm}, \mathrm{h} 1} \exp \left[\left(h_{2}-h_{1}\right) / H\right] .
$$

Generally, density scale height $\mathrm{H}$ varies at different parts of a planet's atmosphere.

We performed a literature search regarding the atmospheres of Saturn and Titan. Little data exists regarding the upper atmospheric densities of these worlds. Tabulated densities are mostly based upon Voyager fly-by data. The density models utilized in this paper are based upon tables for Saturn's atmospheric density $0-400 \mathrm{~km}$ above the visible cloud tops and 0 $400 \mathrm{~km}$ above Titan's surface. ${ }^{9}$

Curve-matching techniques were used to derive from the data in Ref. 9 an approximate equation for Saturn's atmospheric density a height $\mathrm{h} \mathrm{km}$ above the visible cloud tops :

$$
\rho_{\text {sat }, \mathrm{h}}=0.196 \mathrm{e}^{-\mathrm{h} / 44} \mathrm{~kg} / \mathrm{m}^{3} \text {, }
$$

where the density scale height is 44 $\mathrm{km}$. Similiar techniques were used to derive a fairly accurate density profile for Titan in the height (h) range 100-200 km:

$$
\rho_{\text {tit, h }}=0.0226 \mathrm{e}^{-(\mathrm{h}-100) / 37} \mathrm{~kg} / \mathrm{m}^{3},
$$

where density scale height is $37 \mathrm{~km}$. We apply Eq. (5) to the case of Saturn aerocapture by a Configuration 1 sailcraft. The average deceleration is $20 \mathrm{~m} / \mathrm{sec}^{2}$, the average sailcraft velocity relative to Saturn is $36.74 \mathrm{~km} / \mathrm{sec}$ and the 
Configuration 1 areal mass thickness is $0.002 \mathrm{~kg} / \mathrm{m}^{2}$. From Eq. (5), the average density of Saturn's atmosphere encountered by the sailcraft is about $3 \times 10^{-11} \mathrm{~kg} / \mathrm{m}^{3}$. From Eq. (6), this density corresponds to a height above the cloud tops of about $1,000 \mathrm{~km}$. The more conservative Configuration 2 sailcraft has an average deceleration of $4.25 \mathrm{~m} / \mathrm{sec}^{2}$ during aerocapture. It has an areal mass thickness of $0.03 \mathrm{~kg} / \mathrm{m}^{2}$ and an average velocity (relative to Saturn) during aerocapture of $35.7 \mathrm{~km} / \mathrm{sec}$. From Eq. (5), we learn that this sailcraft encounters an average Saturn-atmosphere density during aerocapture of about $10-10 \mathrm{~kg} / \mathrm{m}^{3}$. From Eq. (7), this density corresponds to a height above the Saturn cloud tops of $941 \mathrm{~km}$.

Figure 1 shows an aerocapture trajectory and the parameters used to justify an isodensity-atmosphere approximation. In Fig. 1, $D_{\text {atm }}$ $=$ deceleration distance through Saturn's atmosphere, $h_{0}=$ the sailcraft height above the visible cloud tops at the start and end of the aerocapture pass, $h_{m}=$ sailcraft's mid-point of the aerocapture pass, and $\mathbf{R}_{\text {sat }}=$ Saturn's radius .
Fig. 1. Sail Aerocapture Parameters

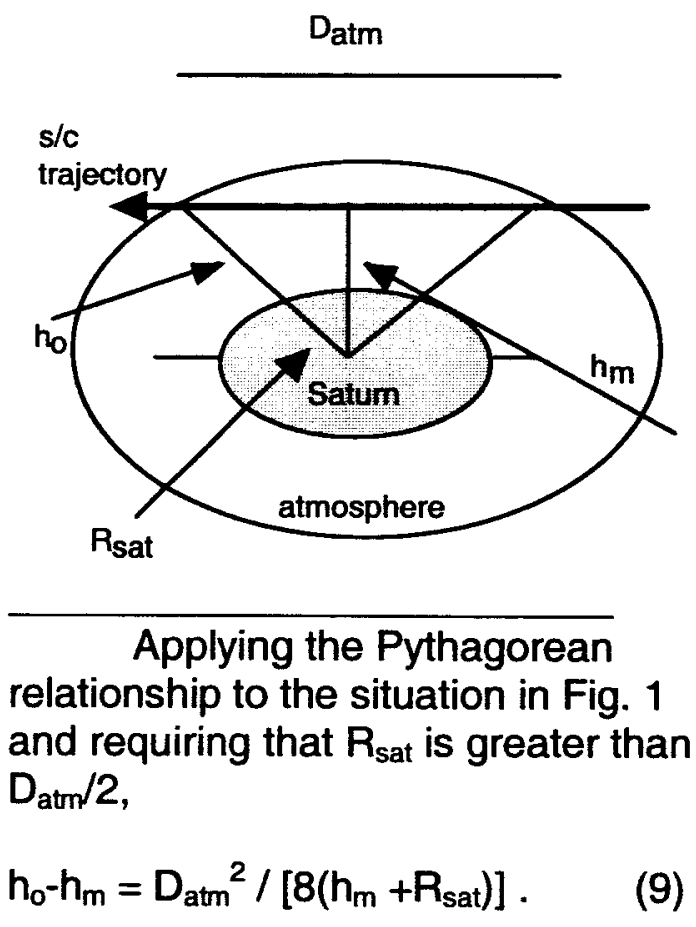

The equatorial radius of Saturn is approximately $60,000 \mathrm{~km}$.

For the Configuration 1 spacecraft, $D_{\text {atm }}=4,630 \mathrm{~km}$ and $h_{m}=$ $1,000 \mathrm{~km}$. Solving Eq. (9), we find that $h_{0}-h_{m}$ is slightly less than $44 \mathrm{~km}$. The corresponding parameters for the Configuration 2 sailcraft are $D_{a t m}$ $=3,534 \mathrm{~km}$ and $h_{m}=941 \mathrm{~km}$. We find in this case that $h_{0}-h_{m}=26 \mathrm{~km}$. Since in both cases $h_{0}-h_{m}$ is less than the density scale height of 44 $\mathrm{km}$, an isodensity atmosphere is a reasonable approximation.

The isodensity approximation was checked for a Neptuneaerocapture trajectory using numerical integration. ${ }^{10}$ It was found that when $h_{0}-h_{m}$ is less than the scale height, using an isodensity atmosphere does not introduce errors greater than a few percent.

(VI) SATURN AEROBRAKING THERMAL CONSIDERATION 
Before considering sail heating during aerocapture, it is worth discussing the physics of the interaction between the sail and atmospheric molecules. As argued in Ref. 10, it is unlikely that atmospheric molecules will pass through the sail because of the spacing of atoms in a solid lattice. Atmospheric molecules are not energetic enough to cause dislocation of atomic planes in the sail. Multiple impacts of atmospheric atoms are required to ionize a sail atom; such ionization is unlikely because of the short lifetime of excited states of sail atoms. in all likelihood, impacting atmospheric atoms will energize sail atoms. These will later decay to the ground state by emitting one or more photons. As evidence of the validity of the assumption that collisions with atmospheric atoms will not unduly damage the sail is the long lifetime of balloon satellites in the upper reaches of Earth's atmosphere.

To estimate sail heating during aerocapture, we first calculate the change in sail kinetic energy and divide by aerocapture duration $(\Delta t)$ to obtain the average power radiated by the sail during the aerocapture pass. Sail irradiance is then calculated by dividing by $2 X$ the sail area, since both sail faces can radiate:

$W_{\text {sail }}=\sigma_{s / c}\left(V_{s / c, o^{2}}-V_{s / c, f^{2}}\right)^{2} /(4 \Delta t)$ watt $/ m^{2}$.

Applying black-body radiation theory, the sail's average radiation temperature is calculated:
$\mathrm{T}_{\text {sail }}=\left[\mathrm{W}_{\text {sail }} /\left(\varepsilon_{\text {sail }} \sigma_{\mathrm{sb}}\right)\right]^{1 / 4} \mathrm{Kelvin}$,

where $\varepsilon_{\text {sail }}$ is the sail emissivity and $\sigma_{\mathrm{sb}}$ is the Stefan-Boltzmann constant $\left(5.67 \times 10^{-8}\right.$ watt- $\left.\mathrm{m}^{-2}-\mathrm{T}^{4}\right)$. Following Mclnnes, we assume a sail emissivity of 0.6. Substitution in Eqs. (10) and (11) for the Configuration 1 sailcraft results in an average sail radiation temperature of 383 degrees Kelvin. The higher areal-mass thickness Configuration 2 sailcraft is found to have an average radiation temperature during aerocapture of 508 degrees Kelvin.

\section{(VII) ORBITING SATURN}

After Saturn aerocapture, the sailcraft emerges from Saturn's upper atmosphere in an elliptical orbit around the planet. As shown in Fig. 2, the periapsis of this orbit is near Saturn, the apoapsis is near Titan. Application of the sail or a small thruster could raise the periapsis above Saturn's upper atmosphere.

Let periapsis radius $r_{\text {per,sat }}=$ Saturn's radius $(60,000 \mathrm{~km})$ and apoapsis radius $r_{a p, \text { sat }}=$ Titan's distance from Saturn $\left(1.22 \times 10^{6} \mathrm{~km}\right)$. The orbital eccentricity $\mathrm{e}_{\text {sat }}$ can be defined: ${ }^{5}$

$e_{\text {sat }}=\left(r_{a p, s a t}-r_{p e r, s a t}\right) /\left(r_{a p, s a t}+r_{p e r, s a t}\right)$.

Substituting in Eq. (11), we find that $e_{\text {sat }}=0.906$. 


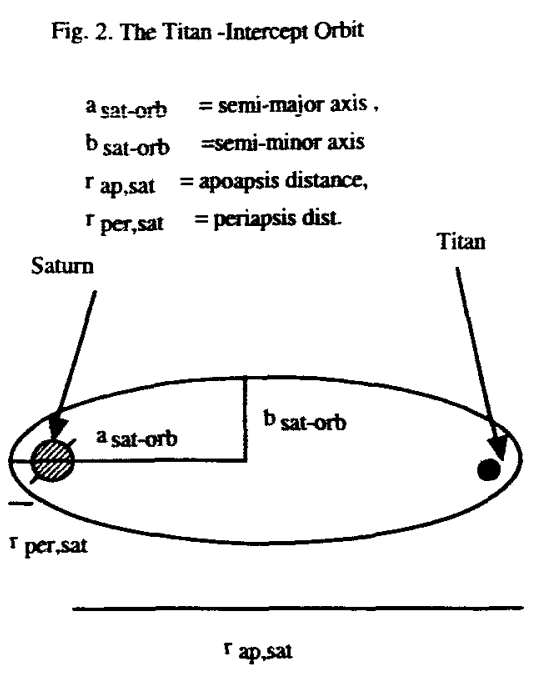

The spacecraft's orbital period around Saturn is calculated, from Ref. 5 and Fig. 2,

$$
\begin{aligned}
& P_{\text {orb }}=2 \pi\left(G_{\text {sat }}\right)^{-1 / 2} a_{\text {sat,ort }}{ }^{3 / 2}, \\
& \quad=2 \pi\left(G_{\text {sat }}\right)^{-1 / 2}\left(r_{\text {ap }, \text { sat }}+r_{\text {per,sat }}\right)^{3 / 2},
\end{aligned}
$$

where $M_{\text {sat }}=$ Saturn's mass $=5.68 \mathrm{X}$ $10^{26} \mathrm{~kg}^{9}$ and $a_{\text {sat-orb }}$ is the semi-major axis of the sailcraft's orbit about Saturn. From Eq. (13), we find that the sailcraft orbits Saturn once every $532,000 \mathrm{sec}$ ( 6.16 days).

To find the sailcraft's aphelion velocity, we next apply a standard equation: ${ }^{9}$

$\mathrm{V}_{\mathrm{ap}, \text { sat }}=$
$2 \pi \mathrm{a}_{\text {sat }-\mathrm{rb}} \mathrm{P}_{\mathrm{orb}}{ }^{-1}\left[\left(1-\mathrm{e}_{\mathrm{sat}}\right) /\left(1+\mathrm{e}_{\text {sat }}\right)\right]^{1 / 2}$. (14)

Substituting in Eq. (14), we find that $V_{a p, s a t}$ is approximately $1.6 \mathrm{~km} / \mathrm{sec}$. Titan orbits Saturn once every 15.95 days at an average distance of $1.22 \times 106 \mathrm{~km}$ from Saturn. Titan's escape velocity is $2.64 \mathrm{~km} / \mathrm{sec} .9$ The average orbital velocity of this satellite is about $5.6 \mathrm{~km} / \mathrm{sec}$.
Assuming that the spacecraft and Titan orbit Saturn in the same direction, the spacecraft's relative velocity to Titan is about $4 \mathrm{~km} / \mathrm{sec}$. Therefore, the sailcraft commences Titan aerocapture with a velocity of $\left(4^{2}+2.64^{2}\right)^{1 / 2}=4.79 \mathrm{~km} / \mathrm{sec}$ relative to Titan. To be captured as a satellite of Titan, the sailcraft must reduce its velocity relative to Saturn by $2.15 \mathrm{~km} / \mathrm{sec}$.

\section{(VIII) TITAN AEROCAPTURE}

Consider a $1-\mathrm{g}(10 \mathrm{~m} / \mathrm{sec} 2)$ average deceleration Titanaerocapture maneuver from a velocity of 4.79 to $2.64 \mathrm{~km} / \mathrm{sec}$ relative to Titan. During aerocapture, the average velocity of the sailcraft relative to Titan is $3.72 \mathrm{~km} / \mathrm{sec}$. The duration of the aerocapture pass is 215 seconds. The distance traversed during aerocapture is about $800 \mathrm{~km}$. For the Configuration 1 spacecraft, we substitute in Eq. (5) and obtain an average density of Titan's atmosphere of about $1.5 \times 10-9$ $\mathrm{kg} / \mathrm{m} 3$ during the aerocapture pass. Applying Eq. (8), this atmospheric density corresponds to an approximate height above Titan's surface of $712 \mathrm{~km}$.

We next apply Eq. (9), using Titan's radius of $2,575 \mathrm{~km}$ in place of Saturn's. We find that $h_{0}-h_{m}=24 \mathrm{~km}$, less than the 37-km density scale height. The isodensity atmosphere approximation therefore is reasonably accurate in this instance. From Eq. (10), the average irradiance of the Configuration 1 sail during aerocapture is about 37 watts. Sail heating is inconsequential.

Because the Configuration 2 spacecraft has a higher areal mass 
thickness, Eq. (5) reveals that the average density of Titan's atmosphere encountered by this spacecraft during aerocapture is about $2.3 \times 10-8 \mathrm{~kg} / \mathrm{m} 3$, which corresponds to an average height of $611 \mathrm{~km}$ above Titan's surface during aerocapture.

Applying Eq. (9), we find that ho-hm $=25 \mathrm{~km}$, still less than the density scale height. In this case also, the isodensity atmosphere is a fair approximation. Equation (10) reveals that the Configuration 2 sail irradiance during Titan aerocapture is approximately 555 watts. From Eq. (11), this corresponds to a temperature of 357 Kelvin for a 0.6 emissivity sail. Sail heating will not be an issue during Titan aerocapture.

\section{(IX) CONCLUSIONS}

We have uncovered no obstacles to a pure solar-photon-sail aerocapture mission to Satum and Titan. Such a mission can be flown using current technology or advanced sail films; the flight durations for advanced sails are greatly reduced. Although we anticipate few problems with sail survivability during aerocapture, we have proposed an experimental procedute to check the validity of our assumptions. ${ }^{10}$

More information on Saturn's and Titan's atmospheres are essential to plan such a mission, however. Mission planners need to know whether reactive chemical species are present in the ionospheres or exospheres of this planet and satellite. Also, are the density profiles considered truly representative of conditions at the aerocapture heights? Do the atmospheric density profiles of Saturn and Titan vary with location or time? Hopefully, these questions and others will be addressed by the near future by the Cassini/Huygens spacecraft.

\section{ACKNOWLEDGEMENTS}

We greatly appreciate the assistance of many people affiliated with Teledyne Brown Engineering in Huntsville, AL including J. Hall, T. Moton, D. Robinson, and R. C. Anding. The encouragement and assistance of many people affiliated with the NASA MSFC, Advanced Space Transportation Directorate solar-sail research team is appreciated. We'd especially like to thank L. Johnson, G. Garbe and E. Montgomery. This research has been supported by NASA MSFC Contract NASA \#H-351191D.

\section{REFERENCES :}

1. G. L. Matloff, G. Vulpetti, C. Bangs and R. Haggerty, "The Interstellar Probe (ISP) : Pre-Perihelion Trajectories and Application of Holography," NASAVCR-2002211730.

2. G. L. Matloff, "Persephone : A Non-Nuclear Rendezvous Mission to a Kuiper Belt Object," in Proc.of Space Technology and Applications International Forum-STAIF 2000, ed.

M. S. El-Genk, AIP (2000).

3. L. Johnson and S. Leifer, "Propulsion Options for Interstellar Exploration," AIAA-2000-3334. 
4. C. R. Mclnnes, Solar Sailing, Springer-Praxis, Chichester, UK (1999).

5. R. R. Bate, D. D. Mueller, and J.

E. White, Fundamentals of

Astrodynamics, Dover, NY (1971).

6. G. L. Matloff, Deep-Space Probes, Springer-Praxis, Chichester, UK (2000).

7. I. Harris and N. W. Spencer, "The Earth's Atmosphere," in Introduction to Space Science, ed. W. N. Hess, Gordon \& Breach, Philadelphis, PA (1965), Chap. 2.

8. B. N. Cassenti, G. L. Matloff, and J. Strobl, "The Structural Response and Stability of Interstellar Solar Sails," JBIS, 49, 345-350 (1996).

9. K. Lodders \& B. Fegley, Jr., The Planetary Scientist's Companion, Oxford University Press, NY (1998).

10. G. L. Matloff and T. Taylor, "The Solar Sail as Planetary Aerobrake," IAC-03-S.6.02. 